\title{
PEMANFAATAN TUNGKU BERBAHAN BAKAR LPG DAN MODIFIKASI RUANG BAKAR UNTUK PEMBAKARAN KERAMIK UKIR BERGLASIR
}

\author{
M. Dachyar Effendi \\ Pusat Teknologi Pengembangan Material \\ BPPT Gedung 2 It. 22, Jl. MH Thamrin no. 8 Jakarta 10340 \\ E-mail : dachyareffendi@yahoo.com
}

\begin{abstract}
A downdraft kiln using LPG as energy source with capacity $1 \mathrm{~m}^{3}$ and maximum firing temperature $1300^{\circ} \mathrm{C}$ has been constructed and midified to give better heat distribution. For firing ceramic process, most of Balinese and Lombok craftsmen use firewood as energy source. This method is inefficient from the production rate. Point of view, downdraft kiln can help the craftsmen to process ceramic easier, faster and cheaper. Downdraft kiln using LPG has been selected as an alternative kiln due to minimum pollutant produced compare with updraft kiln using coal or firewood. The kiln constructed has fulfilled the requirement of kiln firing process quality in which the firing causes sintering process in the ceramics body. The kiln with a capacity of $1 \mathrm{~m}^{3}$ can reach a maximum firing temperature which of $1300^{\circ} \mathrm{C}$. To test this modified kiln, some carved ceramic has burned into the kiln. Carved ceramic has been chosen caused by need more good heat distribution than other ceramic design product and have differ thickennes in all bodies. The final product give a better product whithout defect compare to product burned into unmodified kiln
\end{abstract}

Kata kunci: tungku hemat energi, keramik ukir, stoneware

\section{PENDAHULUAN}

Pembakaran dalam proses pembuatan keramik adalah bagian terpenting dari proses pembuatan keramik itu sendiri. Banyak daerah di Indonesia, Bali dan Lombok khususnya menggunakan kayu sebagai bahan bakar tungkunya. Beberapa jenis keramik memerlukan proses sintering yang sempurna untuk mencapai kualitas yang diinginkanm seperti misalnya keramik stoneware maupun porselin. Keramik jenis ini paling tidak memerlukan pembakaran suhu tinggi diatas $1100^{\circ} \mathrm{C}$ agar kualitas yang diinginkan tercapai.

Sumber daya alam berupa kayu bakar merupakan masalah tersendiri bagi pengrajin keramik. Karena di beberapa tempat kayu bakar sulit didapat, apalagi pada musim penghujan. Kejadian ini menjadi kendala bagi percepatan produksi yang diinginkan.Selain itu, kesulitan mendapatkan kayu bakar berpengaruh pula pada ongkos produksi pembuatan keramik itu sendiri.

Tungku berbahan bakar kayu, sesuai dengan konstruksinya yang open Kiln dan kapasitas panas yang dihasilkan, tidak dapat digunakan untuk pembakaran suhu tinggi. Kreativitas yang dapat dihasilkan pengrajin juga menjadi terbatas.
Kebanyakan pengrajin yang menggunakan tungku ini menghasilkan gerabah sebagai produk utamanya, seperti terjadi di Plered, Jawa Timur, Banyumulek dan Penujak di Lombok (Anonim, 2002)

Tungku berbahan bakar batubara merupakan salah satu alternatif yang mampu mereduksi biaya produksi sampai $25 \%$ yang disebabkan oleh biaya bahan bakar. Keuntungan lain dari jenis tungku ini dibandingkan dengan tungku berbahan bakar kayu adalah mampu mereduksi waktu pembakaran, waktu pendinginan dan peningkatan kualitas barang (Hidayat, Herman. 2002) Namun pengadaan batubara khususnya di Bali dan Lombok merupakan faktor kesulitan tersendiri. Hasil kunjungan lapangan ke sentra pengrajin di Lombok didapatkan kenyataan bahwa kebanyakan batubara didatangkan dari Surabaya. Perlu diperhitungkan juga waktu pengiriman dan jumlah minimal yang harus dikirim. Kebanyakan pengrajin tidak bergabung dalam satu wadah yang memungkinkan mereka untuk memesan suatu barang secara kolektif, khususnya untuk pengrajin tradisional Lombok (Anonim, 2002). 
LPG yang diproduksi oleh PERTAMINA kebanyakan telah terdistribusi sampai ke pelosok-pelosok daerah di Indonesia. Memanfaatkan LPG sebagai bahan bakar tungku pengganti kayu bakar merupakan alternatif yang baik mengingat pengadaan LPG lebih mudah dilakukan oleh pengrajin daripada batubara.Tungku gas yang berdisain Downdraft Kiln mampu memberikan keuntungan yang sama dengan tungku berbahan bakar batubara. Ditambah lagi bahwa tungku gas mudah dalam pengoperasiannya, paling bebas polusi dan dapat dipakai untuk pembakaran reduksi maupun oksidasi. Namun mengingat kemampuan finansial pengrajin keramik pada umumnya, rancangan tungku gas yang murah serta mudah pembuatannya perlu diusahakan agar pengrajin dapat merekonstruksi sendiri sesuai dengan kebutuhan dan kemampuan finansialnya.

Hal yang mendasar dalam perancangan ini adalah, kemudahan mendapatkan LPG. Serta didukung oleh keberadaan peralatan seperti burner, penukar panas, bahan refraktori ringan hemat energi (wool keramik) dan berbagai jenis alat kontrol otomatis, sebagai komponen penyusun kiln, yang mudah didapat dan teknologinya sudah dikuasai.

\section{BAHAN DAN METODE EKSPERIMEN}

Metode yang dipakai adalah mengumpulkan data perancangan downdraft kiln, menguji coba kekuatan bakar tungku dengan melihat proses sintering yang terjadi pada keramik uji. Terakhir adalah menguji karakteristik sampel keramik yang dibakar dalam tungku hasil rancangan pada berbagai tingkatan suhu dengan melihat mengamati kematangan bakar dan kualitas keramik uji berpatokan pada nilai-nilai Susut Kering (SNI 15-0255-1984), Susut Bakar (SNI 15-0255-1984), peresapan air (SNI 12-2580-92) dan penentuan warna.

Penentuan rancangan tungku menerapkan metode sebagai berikut. Tahap pertama, ditentukan ukuran / dimensi tungku yang dinginkan, dalam hal ini ruang bakar tungku ditetapkan $1 \mathrm{~m}^{3}$. Tahap kedua, ditentukan jenis isolasi dan bahan konstruksi tungku, dalam hal ini sebagai isolasi dipakai bata tahan api $(\mathrm{k}=$ $1,07 \mathrm{~W} /\left(\mathrm{m}^{0} \mathrm{~K}\right)$, glasswool. Tahap ketiga, dilakukan perhitungan distribusi suhu pada dinding untuk menentukan tebal dinding ideal dengan menggunakan rumus perpindahan panas konduksi pada keadaan ajeg dua dan tiga arah, dengan menggunakan persamaan-persamaan untuk berbagai bentuk benda dan kedudukan pada perpindahan secara konduksi (Warnijati, 1998).
Cara kerja persiapan sampel dan pengujian sampel keramik mengikuti tahapan sebagai berikut. Pertama dilakukan pengolahan bahan mentah untuk mencapai kehalusan butiran lolos ayakan ukuran lubang $0,125 \mathrm{~mm}$. Bahan badan keramik dibuat dengan komposisi Ballclay Bantur 10\%, Kaolin Belitung 4\%, Felspar RRC 14\%, Tanah putih Kalimantan $70 \%$, Semen Tahan Api $2 \%$. Kedua dilakukan pembuatan sampel untuk penentuan tingkat keplastisan, susut kering, susut bakar, susut jumlah, peresapan air, keporian semu, berat isi, berat jenis semu, warna, tekstur dan suara.

Ke dalam bahan baku kering udara dengan kehalusan butiran dibawah 0,125 $\mathrm{mm}$ ditambahkan air sehingga mencapai air pembentukan optimum. Kemudian ditutup dengan lap basah dan dibiarkan selama \pm 2 jam, supaya terjadi pemerataan kadar air. Campuran lalu diremas-remas dan dibanting-banting cukup lama, supaya airnya merata betul dan terbentuk masa plastis (tidak ada gelembung udara). Sifat plastis ditandai dengan sifat masa yang tidak lengket ketika ditekan dengan jari tangan dan dapat membentuk lingkaran $360^{\circ}$ dengan keliling $10 \mathrm{~cm}$, tebalnya $1 \mathrm{~cm}$ tanpa terjadi retak. Dari masa plastis itu dibentuk sampel dengan menggunakan cetakan kayu yang sebelumnya bagian dalamnya diolesi minyak mineral supaya sampel tidak melekat pada cetakan dan mudah dikeluarkan. Ukuran sampel $\pm 12 \mathrm{~cm} \times 2,5 \mathrm{~cm} \times$ $1,5 \mathrm{~cm}$. Untuk penentuan susut kering dan susut bakar pada tiap tingkat pembakaran digunakan paling sedikit 6 sampel.

Masa plastis yang dimasukkan dalam cetakan sedikit lebih banyak dari yang diperlukan untuk pembentukan benda ujinya, panjangnya dan lebarnya sedikit kurang, tetapi tebalnya lebih. Masanya ditekan dari tengah ketepi hingga cetakannya berisi penuh. Kelebihan masa kemudian dipotong dan permukaannya dibuat licin dengan pisau atau potongan kayu, yang dibasahi. Setelah dibentuk, pada permukaannya diberi tanda garis $10 \mathrm{~cm}$. Sampel ditimbang lalu dibiarkan pada udara terbuka sampai menjadi kering pada papan yang diberi sedikit berminyak.

\subsection{Penentuan Susut Kering (SNI 15-0255- 1984)}

Sampel yang dikeringkan pada papan, pada waktu-waktu tertentu dibalik supaya pengeringannya merata dan mengurangi terjadi kelengkungan. Setelah Sampel menjadi kering (dikontrol dengan penimbangan, selisih berat kurang dari $0,5 \mathrm{~g}$ untuk 2 hari berturut-turut), jarak tanda garis ditentukan dengan mikrometer tepat sampai $0,1 \mathrm{~mm}(\mathrm{p} \mathrm{cm})$, maka susut kering = $(10-p) / 10 \times 100$. Susut kering yang diberikan 
ialah hasil rata-rata susut kering Sampel yang diukur.

\subsection{Penentuan Susut Bakar (SNI 15-0255- 1984)}

Sampel yang telah diukur jarak tanda garisnya $p$ $\mathrm{cm}$, untuk mengetahui susut kering, dibakar dalam tungku laboratorium sampai suhu yang telah ditentukan untuk setiap pembakaran. Kondisi pembakaran sebaiknya netral atau tidak dibuat dengan kondisi pembakaran reduksi ataupun oksidasi,dalam arti, jumlah oksigen yang diperlukan dalam pembakaran tersebut sesuai secara teoritis. Bila tidak memakai tungku listrik, Sampel dimasukkan dalam kapsel atau wadah pelindung supaya terlindung dari api langsung. Kecepatan kenaikan suhu diatur sedemikian, sehingga suhu $900^{\circ} \mathrm{C}$ dapat dicapai dalam waktu 4 - 5 jam, sesudah itu setiap kenaikan $100^{\circ} \mathrm{C}$ dicapai dalam waktu 1 jam.

Setelah pembakaran selesai, sampel dibiarkan menjadi dingin dalam tungku. Jarak tanda garis ditentukan dengan mikrometer tepat sampai $0,1 \mathrm{~mm}(p 1 \mathrm{~cm})$. Susut bakar $=(p-p 1) / p$ $\mathrm{x} 100 \%$ dan susut jumlahnya $=(10-\mathrm{p} 1) / 10 \mathrm{x}$ $100 \%$. Susut bakar atau susut jumlah diberikan sebagai hasil rata-rata semua susut bakar atau susut jumlah sampel yang diukur.

\subsection{Penentuan peresapan air (SNI 12-2580- 92)}

Mula-mula sampel pasca bakar dikeringkan dalam oven pada suhu $105-110^{\circ} \mathrm{C}$, sehingga beratnya tetap. Kemudian didinginkan dalam desikator dan ditentukan berat keringnya ( $D$ gram) dengan ketelitian 0,01 g. Sampel dipanaskan dalam wadah berisi air sampai mendidih dan dibiarkan selama 5 jam. Pasang penyekat atau semacamnya sebagai pemisah antara sampel dengan dinding atau dasar wadah, begitupun antara sampel satu dengan lainnya agar tidak bersentuhan. Kemudian dinginkan selama 24 jam di dalam air, lalu keluarkan dan dilap dengan kain lembab. Sampel segera ditimbang dengan neraca yang ketelitiannya 0,01 $\mathrm{g}(\mathrm{W}$ gram $)$ maka, peresapan airnya adalan $=(\mathrm{W}$ - D)/D x 100\%.

Untuk menentukan keporian semu (KS), berat isi (BI) dan berat jenis semu (BJS), dilakukan penimbangan sampel dalam air (W1 gram), dan selanjutnya dilakukan perhitungan $\mathrm{KS}$, BJI dan BJS dengan persamaan $\mathrm{KS}=(\mathrm{W}$ $\mathrm{D}) /(\mathrm{W}-\mathrm{W} 1) \times 100 \%, \quad \mathrm{Bl}=\mathrm{D} /(\mathrm{W}-\mathrm{W} 1) \quad \mathrm{g} / \mathrm{cm}^{3}$ dan BJS=D/(D-W1) $\mathrm{g} / \mathrm{cm}^{3}$.

\subsection{Penentuan warna, tekstur dan suara}

Selain melakukan pengukuran untuk menentukan susut kering, susut bakar, susut jumlah, peresapan air, keporian semu, berat isi, berat jenis semu, juga dilakukan penentuan warna tekstur dan suara. Warna dan tekstur ditentukan dengan pengamatan secara visual dan penentuan suara dengan memukul salah satu ujung Sampel dengan sesamanya atau benda pejal lainnya. Suara yang terdengar dinyatakan nyaring, agak nyaring atau tidak nyaring yang menyatakan kepadatan badan.

\section{HASIL DAN PEMBAHASAN}

Tungku hasil modifikasi mempunyai kapasitas muat barang $1 \mathrm{~m}^{3}$. Ukuran ini lebih fleksibel dalam menempati ruang produksi, karena kebanyakan pengrajin tidak mempunyai cukup ruang untuk menempatkan peralatan produksi. Kebanyakan ruang produksi terpakai oleh proses pembentukan keramik.

Oleh karena itu perlu dirancang tungku yang berukuran kecil namun juga efisien dalam pemakaian bahan bakar. Tungku mempunyai 6 bagian utama ysg terdiri dari ruang bakar, lorong api, cerobong asap, tutup tungku, burner dan dinding tungku.

Burner diletakkan di bagian bawah yang langsung berhubungan dengan lorong api yang dibuat berada di sisi atas dan bawah dari ruang bakar. Jarak antara cerobong asap dengan dinding tungku sebesar 0,65 meter. Penampang luar tungku berukuran $1 \mathrm{~m} \times 1 \mathrm{~m}$ dengan ruang bakar berbentuk kubus sebesar $1 \mathrm{~m}^{3}$. Untuk tungku modifikasi tutup dengan bentuk silinder, ada penambahan ruang bakar yang luasnya tidak signifikan untuk penambahan volume ruang bakar, sehingga dalam perhitungan volume ruang bakar dianggap tetap $1 \mathrm{~m}^{3}$. Tutup tungku dimodifikasi dengan harapan terjadi aliran berbalik tanpa halangan sudut pada bagian dalam tungku. Aliran berbalik akan menuju kebawah mengikuti lorong api di sisi bawah tungku dan keluar melalui cerobong asap. Juga diharapkan aliran gas panas dari atas ke bawah akan memasuki keramik yang dibentuk berongga sehingga terjadi proses pematangan menyeluruh pada benda keramik yang dibakar. (Gambar 2).

Untuk menentukan tebal isolasi dan distribusi panas pada dinding tungku, dipakai pendekatan perpindahan panas konduksi ajeg dua dan tiga arah, dengan menyelesaikan perhitungan faktor untuk berbagai bentuk benda dan kedudukan pada perpindahan secara konduksi (Warnijati, Sri., 1988) dengan asumsi 1) sistem dalam keadaan ajeg 2) sifat-sifat bahan tetap, suhu permukaan dalam tungku diambil suhu tertinggi $1300^{\circ} \mathrm{C}$ dan suhu permukaan luar $30^{\circ} \mathrm{C}$, maka ditetapkan tebal isolasi jenis glasswool $12,5 \mathrm{~cm}$ (5 lapis $\times 2,5 \mathrm{~cm}$ tebal glasswool sesuai pabrik), bata isolasi setebal $15 \mathrm{~cm}$ juga disesuaikan 
dengan dimensi bata tahan api di pasaran. Kerangka atau frame dibuat dari baja setebal 3 $\mathrm{mm}$ dua lapis pada bagian tutup dan satu lapis pada dasar dan dinding bawah tungku (lihat Gambar 2)

Tungku dilengkapi dengan alat kontrol untuk mengatur suhu pembakaran dan waktu pembakaran dengan pengaturan dan peletakan alat kontrol seperti ditunjukkan dalam skema berikut di bawah ini

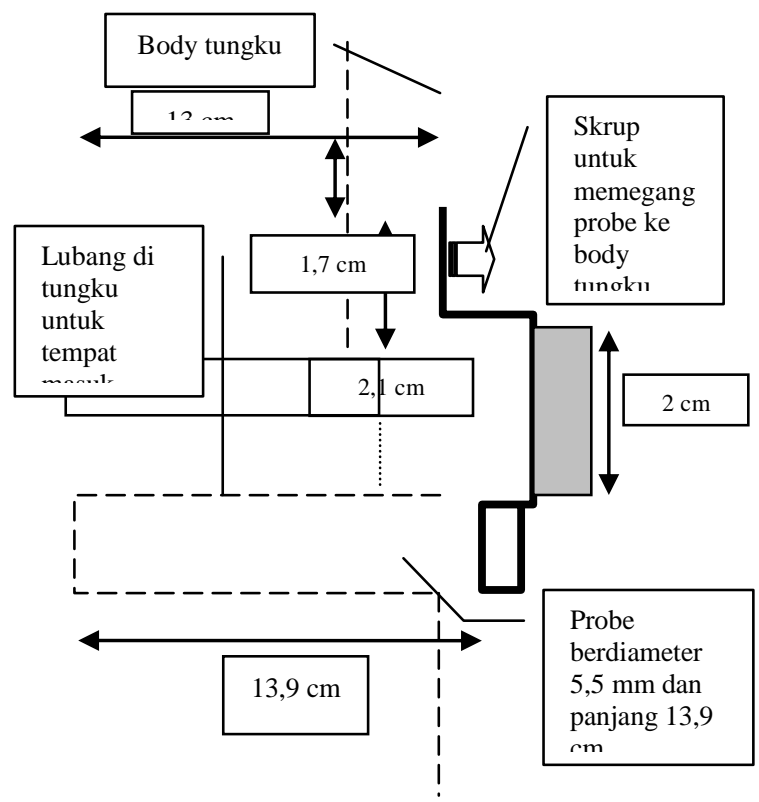

Gambar 1. Skema alat kontrol pada tungku

Gambar modifikasi tungku, bagian-bagian, serta ukurannya, dapat dilihat dibawah ini :

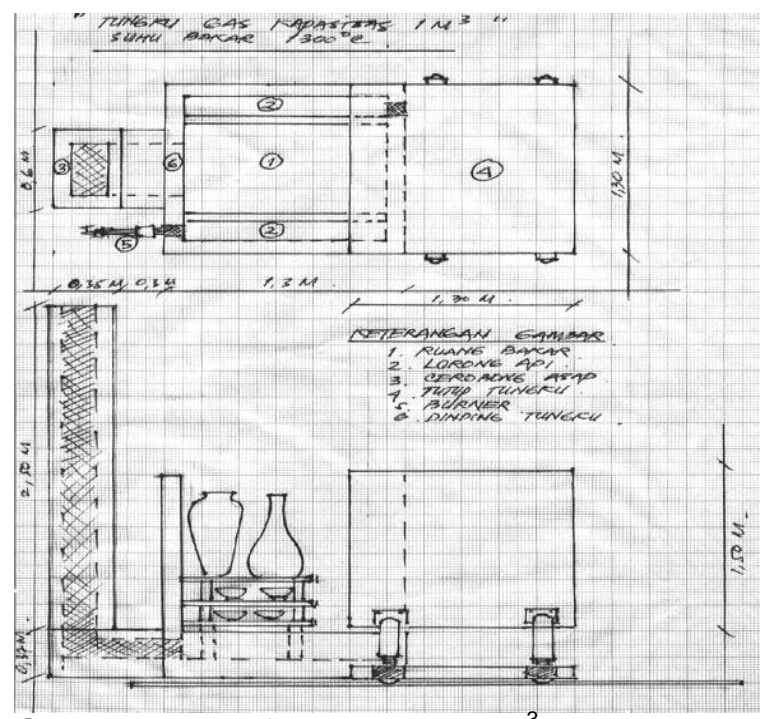

Gambar 2. Modifikasi Tungku $1 \mathrm{~m}^{3}$

Untuk melihat unjuk kerja tungku hasil modifikasi dibuat contoh keramik ukir dengan komposisi seperti dalam Tabel 1, yang dibakar pada beberapa level suhu. Hasil yang didapat dicantumkan dalam Tabel 2

Tabel 1. Formula Bahan Bakun yang Dibuat

\begin{tabular}{|c|c|c|c|c|c|}
\hline \multirow{2}{*}{$\mathrm{No}$. } & \multirow{2}{*}{$\begin{array}{c}\text { Parameter Yang } \\
\text { Diuji }\end{array}$} & \multicolumn{3}{|c|}{ Suhu Bakarar $\left.{ }^{\circ} \mathrm{C}\right)$} & \multirow{2}{*}{ Nilai Standar } \\
\hline & & 900 & 1200 & 1250 & \\
\hline 1. & Wama & Coklat & Kecokklatan & Kelabutua & Puth-coklat \\
\hline 2. & Suara & Tidak nyaring & Agak nyaring & Nyaring & nyaring \\
\hline 3. & Keplasisisan & & Sangat Plastis & & Plasilis \\
\hline 4. & Susust Kering $(\%)$ & & $8,8889 \pm 0,2311$ & & $<9$ \\
\hline 5. & Susut bakar (\%) &. \pm & $4,6569 \pm 0,4472$ & $7,4644 \pm 0,4282$ & $<8$ \\
\hline 6. & Susurt jumlah $(\%)$ & $8,8889 \pm 0,2316$ & $13,1313 \pm 0,4229$ & $15,6902 \pm 0,4157$ & $<18$ \\
\hline 7. & Peresapan Air ( $\%)$ & $18,1170 \pm 0,2176$ & $9,0629 \pm 0,1100$ & $2,1833 \pm 0,1540$ & $\begin{array}{c}<3 \text { (ASTM) atau } 5 \\
\text { (Rhodes) }\end{array}$ \\
\hline 8. & Keporian Semu $(\%)$ & $30,8825 \pm 0,3312$ & $17,6128 \pm 0,4285$ & $4,6329 \pm 0,2913$ & $\cdot$ \\
\hline 9. & Bu is (grlcm') & $1,7048 \pm 0,0093$ & $1,9439 \pm 0,0244$ & $2,1257 \pm 0,0375$ & $2,1-2,3$ \\
\hline 10. & Busemu (grcm?' & $2,4667 \pm 0,0183$ & $2,3598 \pm 0,0348$ & $2,2290 \pm 0,0386$ & \\
\hline
\end{tabular}

Tabel 2. Sifat-sifat fisik terukur massa raga stoneware berkode $\mathrm{R}-1$

\begin{tabular}{|c|c|}
\hline \multirow{2}{*}{ Prosentase } & Kode Bahan Baku \\
\cline { 2 - 2 } Bahan Mentah & $\mathrm{R}-1$ \\
\hline Lempung Kalimantan & 52,50 \\
\hline Lempung Penujak & 10,00 \\
\hline Felspar RRC & 16,00 \\
\hline Talk & 5,50 \\
\hline Kapur & 2,50 \\
\hline Ballclay & 13,50 \\
\hline
\end{tabular}

Secara teknis, penyalaan tungku tidak menemui hambatan. Sampel dibakar dalam ruang bakar tungku hasil rancangan pada berbagai sudut ruangan dengan tingkat pembakaran $1100,1150,1200$ dan $1250^{\circ} \mathrm{C}$.

Mutu atau kualitas badan keramik contoh dapat ditentukan dari susut bakar, susut jumlah, peresapan air, suara ketukan pada badan, dan warna badan keramik setelah dibakar.

Susut bakar bakar ini disebabkan karena terjadinya penguapan sisa air pembentukan (air mekanis) yang belum keluar sempurna waktu pengeringan, pelepasan air kimia, dekomposisi senyawa karbonat, oksidasi senyawa organik (karbon), peleburan feldspar dan kuarsa yang mengakibatkan perubahan ukuran butiran pori. Setelah proses ini selesai, penyusutan tidak terjadi lagi (Suparta, 1997).

Pada suhu bakar $1100-1250^{\circ} \mathrm{C}$, badan mengalami penyusutan sebesar $10,0 \%$ atau 
angka yang termasuk mempunyai resiko tinggi dalam level penyusutan yang dianggap ideal yaitu maksimum sebesar 6\% (Supomo, 1998). Namun angka ini dapat ditoleransi oleh unsurunsur kekuatan badan sehingga cacat badan tidak terjadi secara nyata. Sedangkan susut jumlah adalah penyusutan yang terjadi dari keadaan basah (plastis) sampai pembakaran akhir 19,0\%. Angka ini diperlukan berkaitan dengan disain produk. Namun hal ini tidak berakibat merugikan pada badan secara signifikan. Terbukti juga dari penampakan visual tidak tampak adanya perubahan bentuk, retak, pecah maupun kecenderungan buruk lainnya

Warna badan pada keadaan kering adalah krem karena pengaruh unsur pengotor pada bahan baku. Warna pasca bakar memegang peranan penting. Warna putih atau gading disukai untuk barang pecah belah dan warna gelap disukai untuk barang seni, genteng dan sebagainya karena menghendaki penampilan bersifat alami. Tetapi dengan adanya teknologi glasir rasanya tidak ada masalah dengan warna putih, putih gading, krem atau gelap, karena penampilan dapat ditutup dengan penerapan glasir. Untuk semua level suhu bakar diperoleh warna putih pucat karena pada bahan dalam komposisi mengandung ketidakmurnian yang dapat mempengaruhi tingkat kecerahan warna.

Suara merupakan indikator kepadatan suatu badan keramik. makin padat suatu badan suara makin nyaring. Hasil pengamatan dengan memukul badan uji dengan sesama atau logam menghasilkan suara yang agak nyaring (suhu bakar $1100^{\circ} \mathrm{C}$ ) dan nyaring (suhu bakar 1150 $1250^{\circ} \mathrm{C}$ ). Hal ini sesuai dengan hasil pengujian peresapan air yang menghasilkan angka untuk mengindikasikan tingkat kepadatan. Peresapan air berkaitan tingkat kepadatan badan. Makin kecil peresapan airnya berarti badan semakin padat. Kepadatan merupakan indikator kekuatan suatu bahan.

Pada suhu bakar 1100, 1150, 1200 dan $1250^{\circ} \mathrm{C}$ dicapai peresapan air berturut-turut $7,79 \%, 5,97 \%, 5,07 \%$ dan 2,58\%. Dalam hal ini angka yang termasuk dalam level peresapan air untuk keramik stoneware dengan ketentuan peresapan air 0,5-3\% menurut ASTM (Oishi, T) adalah dengan suhu bakar $1250^{\circ} \mathrm{C}$. Jadi pada suhu $1250^{\circ} \mathrm{C}$ tingkat kepadatan badan ini dapat dianggap sudah memenuhi persyaratan secara teknis untuk badan keramik stoneware. Hal ini

juga menandakan bahwa tungku hasil rancangan cukup layak untuk dipakai menghasilkan keramik stoneware dengan suhu bakar optimum $1250^{\circ} \mathrm{C}$.

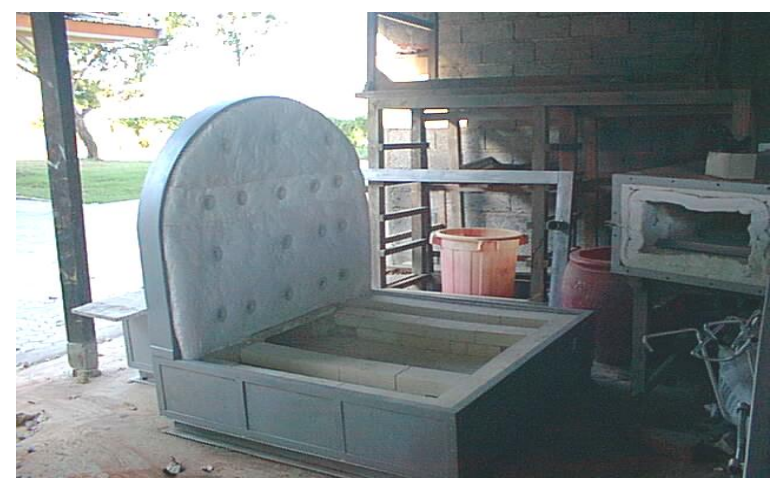

Gambar 3. Tungku tampak samping-belakang

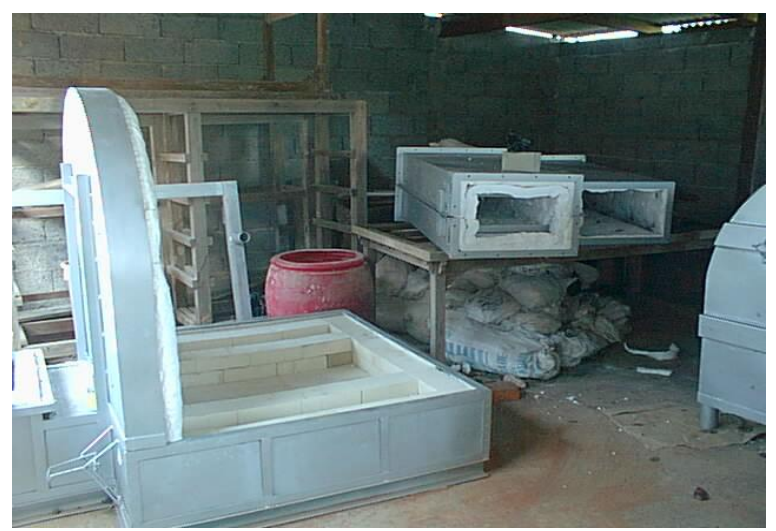

Gambar 4. Tungku tampak samping-depan

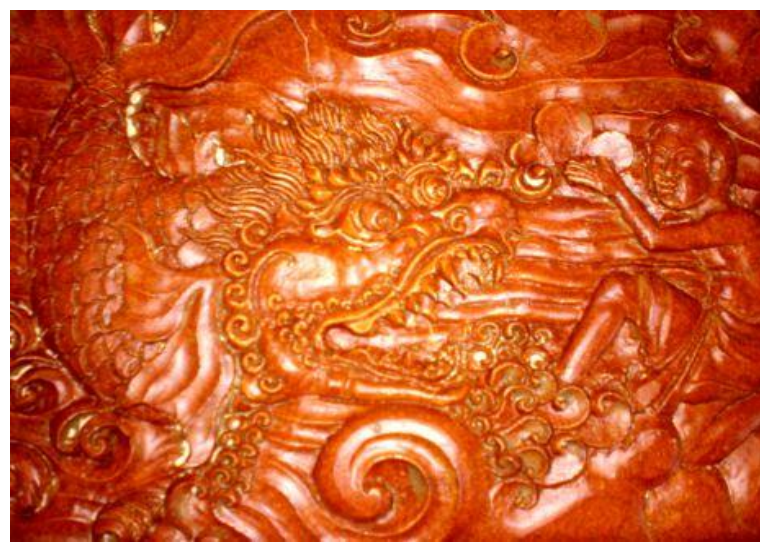

Gambar 5. Hasil akhir produk ukir berglasir yang dibakar memanfaatkan tungku

Hasil akhir produk ukir berglasir yang dibakar dengan memanfaatkan tungku berbahan bakar LPG hasil modifikasi ini, secara visual menunjukkan hasil yang memuaskan, detail yang terlihat rapi dan warna yang diinginkan tercapai

\section{KESIMPULAN}

Tungku dengan kapasitas $1 \mathrm{~m}^{3}$ berbahan bakar LPG hasil modifikasi dapat dipakai sebagai tungku untuk pembakaran keramik ukir yang selama ini bermasalah karena keunikan bentuknya yang mempunyai ketebalan yang tidak sama pada berbagai sisi. Hal ini memerlukan 
modifikasi ruang bakar dan penempatan tungku (burner) agar distribusi panas bisa dipastikan merata dan tidak adanya masalah dengan bagian-bagian produk yang berbeda tingkat kematangannya.

Pemilihan gas sebagai sumber energi tungku disebabkan kemudahan diperolehnya LPG melalui distributor PERTAMINA yang sudah merambah sampai ke daerah-daerah. Tungku berbahan bakar LPG relatif tidak menimbulkan polusi berupa asap dan jelaga, sehingga kualitas keramik hasil produksi lebih bisa diperteanggung jawabkan.Hasil pengujian pada sampel keramik yang dibakar pada tungku hasil rancangan menunjukkan bahwa tungku dapat membakar keramik sampai suhu $1250^{\circ} \mathrm{C}$ sebagi suhu maksimum operasional sedikit dibawah suhu maksimum perancangan $1300^{\circ} \mathrm{C}$ dengan pertimbangan faktor keamanan. Pada suhu tersebut, sampel mempunyai karakteristik sebagai keramik stoneware yang memenuhi syarat ASTM.

\section{DAFTAR PUSTAKA}

Anonim, 2002, Peningkatan Teknologi Dan Pemberdayaan Industri Kecil Keramik Desa Penujak - Lombok. Laporan IPTEKDA t.a. 2002, hal $3-8$,

Hidayat, Herman. 2002. Utilization of Coal in Updraft Kiln for Traditional Fired ClayTiles Industries. Coal tech Proceedings,

Supomo, 1998. Karakterisasi dan Pengendalian Bahan mentah Keramik, Diklat Quality Control Supervisor Industri Keramik Saniter dan Tableware, BBIK

Suparta, AR., Hamzah, F., Soesilowati, 1997. "Hitung Keramik", Balai Besar Industri Keramik, Bandung

Warnijati, Sri., 1988. Perpindahan Panas Konduksi dan Radiasi. PAU UGM 